\title{
COMPETÊNCIAS SOCIOEMOCIONAIS EM PUBLICAÇÕES EM EDUCAÇÃO NOS ÚLTIMOS CINCO ANOS: UMA BREVE REVISÃO
}

\section{ARTIGO ORIGINAL}

FERREIRA, Ricardo Batista 1, FECURY, Amanda Alves ${ }^{2}$, OLIVEIRA, Euzébio de ${ }^{3}$, DENDASCK, Carla Viana ${ }^{4}$, DIAS, Claudio Alberto Gellis de Mattos ${ }^{5}$

FERREIRA, Ricardo Batista. Et al. Competências socioemocionais em publicações em educação nos últimos cinco anos: uma breve revisão. Revista Científica Multidisciplinar Núcleo do Conhecimento. Ano. 07, Ed. 01, Vol. 04, pp. 131 145. Janeiro de 2022. ISSN: 2448-0959, Link de acesso: https://www.nucleodoconhecimento.com.br/educacao/publicacoes-em-educacao

${ }^{1}$ Pedagogo e Comunicador Social, Especialista em Educação Profissional (FATECH), Neuropsicopedagogia (FACEL), e Gestão, Orientação e Supervisão Escolar (FIAR). Discente do Programa de Pós-Graduação em Educação Profissional e Tecnológica (PROFEPT IFAP).

2 Biomédica, Doutora em Doenças Tropicais, Professora e pesquisadora do Curso de Medicina do Campus Macapá, Universidade Federal do Amapá (UNIFAP).

3 Biólogo, Doutor em Doenças Tropicais, Professor e pesquisador do Curso de Educação Física da Universidade Federal do Pará (UFPA).

4 Teóloga, Doutora em Psicanálise Clínica. Atua há 15 anos com Metodologia Científica ( Método de Pesquisa) na Orientação de Produção Científica de Mestrandos e Doutorandos. Especialista em Pesquisas de Mercado e Pesquisas voltadas à área da Saúde. Doutoranda em Comunicação e Semiótica (PUC SP).

${ }^{5}$ Biólogo, Doutor em Teoria e Pesquisa do Comportamento, Professor e pesquisador do Curso de Licenciatura em Química do Instituto de Ensino Básico, Técnico e Tecnológico do Amapá (IFAP) e do Programa de Pós Graduação em Educação Profissional e Tecnológica (PROFEPT IFAP).

RC: 105205

Disponível em: https://www.nucleodoconhecimento.com.br/educacao/publicacoes-emeducacao 


\section{RESUMO}

O conceito de competência é composto pelas nossas ações racionais e emocionais influenciadas por fatores socioculturais. A competência aliada ao controle das emoções em situação social facilita a resolução de conflitos. O objetivo deste trabalho foi fazer uma revisão bibliográfica sobre competências emocionais em educação presentes em publicações nos últimos cinco anos. O método utilizado foi uma breve revisão bibliográfica sobre competências socioemocionais em publicações sobre educação entre 2017 e 2021, em língua portuguesa, em bases de dados de pesquisa Google Acadêmico. É preciso identificar quais competências são necessárias e quais podem ser desenvolvidas no ambiente escolar. As políticas educacionais parecem exigir a inclusão de competências socioemocionais nos currículos da educação básica, porém ocorre a falta de capacitação dos professores. A reestruturação dos currículos deveria também abranger situações diárias de ensino que fossem possíveis de serem realizadas, a partir da reorganização dos espaços pedagógicos, alinhado às estratégias de ensino fundamentadas nas competências. A modernização dos currículos com a inclusão de competências socioemocionais proporciona aos alunos uma formação integral (omnilateral). Na Educação profissional e Tecnológica (EPT) o saber técnico-profissional deve ser para além de uma formação de conteúdo, preparando os discentes para enfrentarem situações reais da futura profissão. A vida adulta, e a vida no trabalho, exige comportamentos e conhecimentos que o aluno utilizará em sua prática social e profissional, fora do ambiente escolar.

Palavras-chave: Educação, Ensino, EPT, Competência Socioemocional.

\section{INTRODUÇÃO}

O conceito de competência é amplo, multidisciplinar e com vários significados possíveis. É composto pelas nossas ações racionais e emocionais influenciadas por fatores socioculturais. Pode ser aprendida de diversas maneiras, em ambientes escolares ou não. As competências se modificam conforme a sociedade e isso

RC: 105205

Disponível em: https://www.nucleodoconhecimento.com.br/educacao/publicacoes-emeducacao 
influencia nos perfis profissionais exigidos pelas empresas e também pela área educacional. Ser competente é mobilizar recursos, comportamentos e conhecimentos e articulá-los para traçar um caminho seguro diante de uma demanda que requer a tomada de decisões no enfrentamento de situações problemas (Perrenoud, 2014; Marinho-Araujo e Rabelo, 2015) (Figura 1).

Figura 1. Mostra as fases para o desenvolvimento de competência

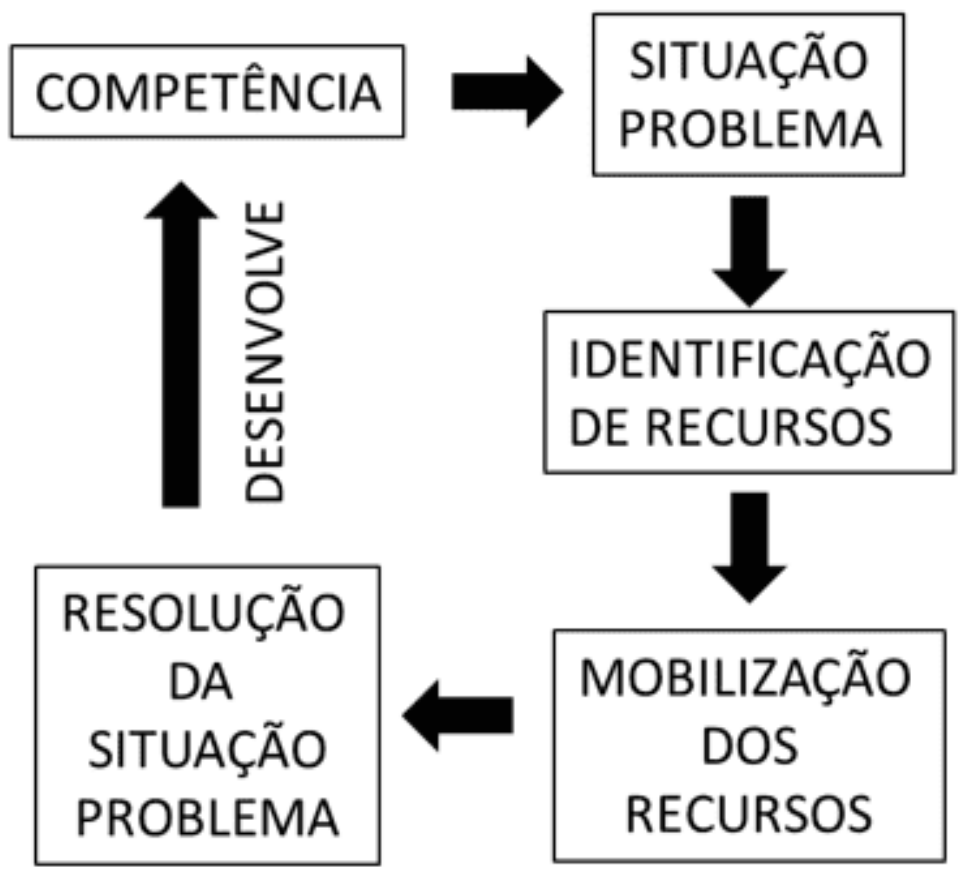

Adaptado de Marinho-Araujo e Rabelo (2015)

No reino animal, incluindo a espécie humana, o termo social pode significar que existe uma regra que dita a conduta dos seres vivos no seu grupo (Carvalho, 1994). No grupo dos seres humanos o conceito de "social" indica que os indivíduos criam, aprendem e seguem normas para convivência (Moraes, 2020).

Emoções podem ser caracterizadas por um conjunto de circunstâncias onde experiências pessoais podem ativar respostas, perceptíveis ou não, no corpo do indivíduo. Essas experiências podem ocorrer com o próprio indivíduo (seus

RC: 105205

Disponível em: https://www.nucleodoconhecimento.com.br/educacao/publicacoes-emeducacao 
pensamentos e como o mundo o afeta); entre ele e outro; e em contexto social. As reações às experiências que o sujeito tem pode levar a diferentes comportamentos, como por exemplo, enfrentar uma situação adversa; desviar-se ou fugir dela; tomar decisões baseado em aprendizado com situações anteriores; reconhecer emoções de outros pela expressão facial e corporal. As emoções são consideradas benéficas quando auxiliam na tomada de decisões, ajudando a alcançar objetivos, e motivando comportamentos socialmente aceitos. Podem ser consideradas prejudiciais quando sua frequência ultrapassa limites na tomada de decisões levando ao comportamento negativo e ao não cumprimento de um objetivo desejado (Morais, 2019).

A competência socioemocional é uma característica de indivíduos que apresentam um autocontrole comparativamente acima da média. A competência aliada ao controle das emoções em situação social facilita a resolução de conflitos, pessoais ou interpessoais, de forma construtiva e criativa. O desenvolvimento deste tipo de competência contribui para a formação integral da pessoa (Carvalho e Silva, 2017; Azevedo, 2019; Cericato e Cericato, 2019; Gonçalves, 2019; Silva, 2019).

As demandas da sociedade moderna exigem um novo perfil profissional, que seja capaz de atender as complexidades dos problemas sociais. Diante desse cenário, a educação passa a considerar não só os aspectos cognitivos do aluno, mas também as características emocionais e sociais, incluindo novos conhecimentos para enfrentar os desafios, que envolvem não somente a formação intelectual, mas a formação integral (Carneiro e Lopes, 2020; Silva, 2020; Barreto, 2021).

O desenvolvimento das competências socioemocionais na escola permite ao aluno exercer autonomia e responsabilidade por suas atitudes, e colabora para a preservação da sua saúde mental. Dessa forma, desenvolver competências socioemocionais na escola contribui para uma atitude preventiva, evitando situações de bullying, ansiedade, depressão e outros tipos de transtornos. Ao desenvolver essas competências os alunos passam a ter maior empatia com o próximo, respeitando as individualidades, os limites pessoais e melhorando a qualidade das relações atuais e

RC: 105205

Disponível em: https://www.nucleodoconhecimento.com.br/educacao/publicacoes-emeducacao 
futuras (Carneiro e Lopes, 2020; Silva, 2020). Incluindo em seu currículo estratégias educativas para o desenvolvimento das competências socioemocionais, as instituições de ensino contribuem para a formação humana e integral do aluno, permitindo que ele seja capaz de superar e resolver os problemas complexos e ter uma vida profissional de sucesso (Silva, 2020; Barreto, 2021).

A Constituição Federal de 1988 assegura que a oferta da Educação no Brasil é direito de todos e tem como objetivo garantir o pleno desenvolvimento da pessoa e a preparar para o exercício da cidadania e da qualificação para o trabalho (Brasil, 2019). A Lei de Diretrizes e Bases da Educação Nacional (LDB), que surge em decorrência da Constituição Federal de 1988, afirma que a oferta da educação escolar deve ter relação com o mundo do trabalho e a prática social (Brasil, 1996).

As Diretrizes Curriculares Nacionais Gerais para a Educação Profissional e Tecnológica (EPT), advinda das resoluções da LDB, adequou seus currículos para acompanhar as mudanças ocorridas na formação sócio-ocupacional do trabalho e as exigências da formação profissional nos diferentes níveis de desenvolvimento, visando a construção de competências técnico-profissionais. Portanto a EPT deve considerar o trabalho como princípio educativo, integrando em sua organização curricular saberes cognitivos e socioemocionais, visando desenvolver competências profissionais que garantam o pleno desenvolvimento do sujeito, preparando para o exercício da cidadania e sua formação para o mundo do trabalho (Brasil, 2021).

As competências socioemocionais são definidas no $§ 2^{\circ}$ do artigo Art. 20 das Diretrizes Curriculares Nacionais Gerais para EPT como sendo:

(...) parte integrante das competências requeridas pelo perfil profissional de conclusão podem ser entendidas como um conjunto de estratégias ou ações que potencializam não só o autoconhecimento, mas também a comunicação efetiva e o relacionamento interpessoal, sendo que entre estas estratégias destacam-se a assertividade, a regulação emocional e a resolução de problemas, constituindo-se como competências que promovem a otimização da interação que o

RC: 105205

Disponível em: https://www.nucleodoconhecimento.com.br/educacao/publicacoes-emeducacao 
indivíduo estabelece com os outros ou com o meio em geral. (Brasil, 2021. p, 8).

Segundo a BNCC as competências devem ser incorporadas também na educação básica, assegurando o direito de aprendizagens essenciais, com foco no desenvolvimento da educação integral do aluno.

$\mathrm{Na}$ BNCC, competência é definida como a mobilização de conhecimentos (conceitos e procedimentos), habilidades (práticas, cognitivas e socioemocionais), atitudes e valores para resolver demandas complexas da vida cotidiana, do pleno exercício da cidadania e do mundo do trabalho (Brasil, 2017), p. 9).

A EPT deve, em seus cursos técnicos de nível médio nas formas integrada e concomitante, seguir a disposições referentes à Base Nacional Comum Curricular (BNCC) do Ensino Médio, garantindo aos estudantes desenvolvimento e conhecimento evidenciado em práticas cognitivas, profissionais, socioemocionais, valores e emoções, integrados em competências profissionais (Brasil, 2021).

\section{OBJETIVO}

Fazer uma revisão bibliográfica sobre competências emocionais em educação presentes em publicações nos últimos cinco anos.

\section{MÉTODO}

Foi realizada uma breve revisão bibliográfica sobre competências socioemocionais em publicações sobre educação entre 2017 e 2021, em língua portuguesa, em bases de dados de pesquisa Google Acadêmico. Para tal utilizou-se as palavras-chave (ou descritores) "Competências socioemocionais e educação", "Competências Socioemocionais e ensino", e "Competências socioemocionais e educação profissional". Isso possibilita que a revisão seja feita baseada nas mais atualizadas produções acadêmicas (Capes, 2012).

RC: 105205

Disponível em: https://www.nucleodoconhecimento.com.br/educacao/publicacoes-emeducacao 


\section{RESULTADOS}

A tabela 1 mostra a quantidade de artigos encontrada por descritor pesquisado e a quantidade de artigos utilizados na revisão. Mostra também os autores e anos das publicações utilizadas.

Tabela 1 - Quantidade de artigos encontrados e utilizados, de acordo com cada descritor, e seus respectivos autores e anos.

\begin{tabular}{|c|c|c|c|c|}
\hline BASE DE DADOS & DESCRITOR & \begin{tabular}{|c|} 
NUMERO \\
ARTIGOS \\
ENCONTRADOS
\end{tabular} & $\begin{array}{c}\text { NUMERO } \\
\text { ARTIGOS } \\
\text { UTILIZADOS }\end{array}$ & $\begin{array}{c}\text { AUTOR E ANO DOS ARTIGOS } \\
\text { UTILIZADOS }\end{array}$ \\
\hline \multirow{14}{*}{ Google acadêmico } & \multirow{8}{*}{$\begin{array}{c}\text { Competências } \\
\text { socioemocionais e } \\
\text { Educação }\end{array}$} & \multirow{8}{*}{8.300 artigos } & \multirow{8}{*}{8 artigos } & (MARIN et al., 2017) \\
\hline & & & & (CHAVES E HAIASHIDA, 2021) \\
\hline & & & & (SANTOS E ALVES, 2020) \\
\hline & & & & (BISSARO E SANTOS, 2020) \\
\hline & & & & (SCHORN E SEHN, 2021) \\
\hline & & & & (SILVA et al., 2020) \\
\hline & & & & (CARNEI RO E LOPES, 2020) \\
\hline & & & & (LISBOA E ROCHA, 2021) \\
\hline & \multirow{5}{*}{$\begin{array}{c}\text { Competências } \\
\text { Socioemocionais e } \\
\text { Ensino }\end{array}$} & \multirow{5}{*}{7.970 artigos } & \multirow{5}{*}{5 artigos } & (ROCHA E SAMPAIO, 2021) \\
\hline & & & & (BARRETO, 2021) \\
\hline & & & & (SANTOS et al., 2018) \\
\hline & & & & (MARQUESI et al., 2019) \\
\hline & & & & (OLIVEIRA, 2018) \\
\hline & Competências & 1 artigo & 1 artigo & (IGNÁCIO et al., 2021) \\
\hline
\end{tabular}

Fonte: Google acadêmico.

Os resultados e conclusões dos artigos sobre o descritor "competências socioemocionais e educação" com método, autor e ano de cada artigo são mostrados na tabela 2.

RC: 105205

Disponível em: https://www.nucleodoconhecimento.com.br/educacao/publicacoes-emeducacao 
Tabela 2 - Resultados e conclusões dos artigos sobre o descritor "competências socioemocionais e educação" com método, autor e ano de cada artigo.

\begin{tabular}{|c|c|c|c|}
\hline AUTORE ANO & TIPODE MËTODO & RESULTADOS & CONCLUSĀO \\
\hline (MARIN et al., 2017) & Artigo de revsăo & 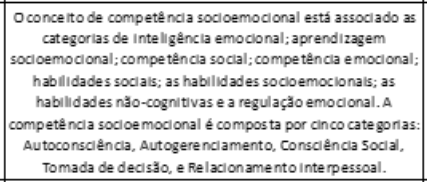 & 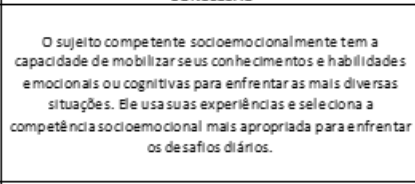 \\
\hline $\begin{array}{c}\text { (CHAVES E HALASHIDA, } \\
2021 \text { ) }\end{array}$ & Artigo de revsăo & $\begin{array}{c}\text { Neces sid ade de incorporaç ăo da educaçăo emocional na } \\
\text { escol a para formaçăo de suje itos integros, com mals respelto, } \\
\text { tolerancla e paclancla. }\end{array}$ & 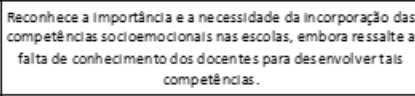 \\
\hline (SANTOS E ALVES, 2020) & $\begin{array}{l}\text { Pesquisa } \\
\text { qualitativa de } \\
\text { caráter } \\
\text { exploratório }\end{array}$ & 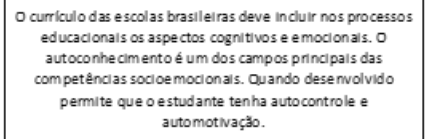 & 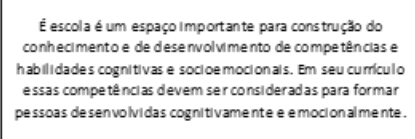 \\
\hline $\begin{array}{c}\text { (BISSARO ESANTOS, } \\
\text { 2020) }\end{array}$ & $\begin{array}{l}\text { Pesquisa } \\
\text { bibliográfica. }\end{array}$ & 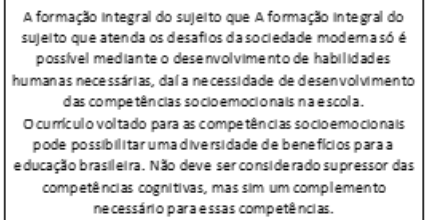 & 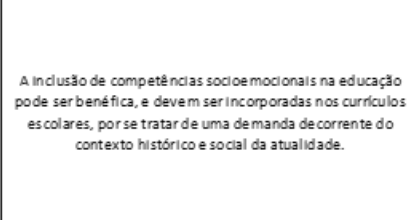 \\
\hline SCHORN E SEHN, 2021) & \begin{tabular}{|c|} 
Revisão narrativa \\
de liter ratura
\end{tabular} & 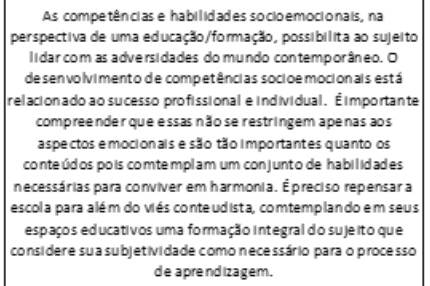 & 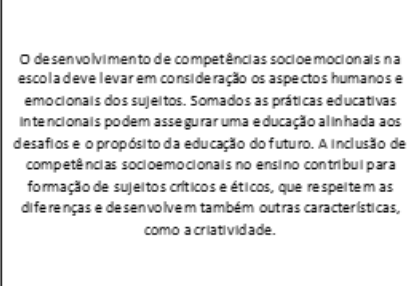 \\
\hline (SILVA et al, 2020) & $\begin{array}{c}\text { Pesqulsa } \\
\text { biblilográfica }\end{array}$ & 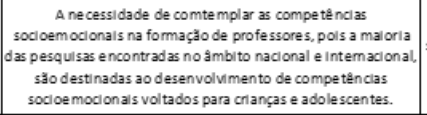 & 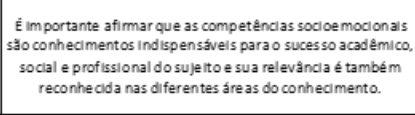 \\
\hline $\begin{array}{l}\text { (CARNEIRO E LOPES, } \\
\text { 2020) }\end{array}$ & $\begin{array}{l}\text { Pe squisa de scritiva } \\
\text { e de campo, como } \\
\text { uso de entrevista } \\
\text { semle struturada } \\
\text { analisa de forma } \\
\text { qual tativa. }\end{array}$ & 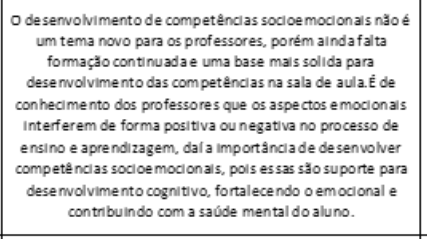 & 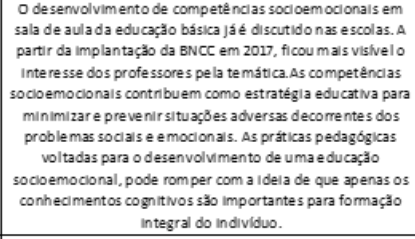 \\
\hline (ULBOA E ROCHA, 2021) & $\begin{array}{l}\text { Pesquisa } \\
\text { qualitativa com } \\
\text { uso } \\
\text { levantamento } \\
\text { blbiliografico }\end{array}$ & 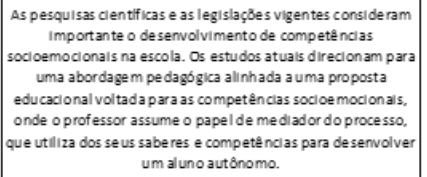 & 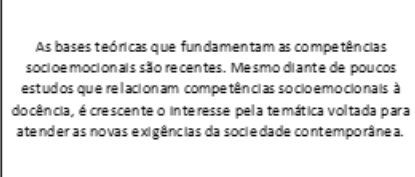 \\
\hline
\end{tabular}

Fontes: (Marin et al., 2017; Bissaro e Santos, 2020; Carneiro e Lopes, 2020; Santos e Alves, 2020; Silva et al., 2020; Chaves e Haiashida, 2021; Lisboa e Rocha, 2021; Schorn e Sehn, 2021)

RC: 105205

Disponível em: https://www.nucleodoconhecimento.com.br/educacao/publicacoes-emeducacao 
Os artigos sobre o descritor "competências socioemocionais e ensino", seus resultados e conclusões, seus métodos, autores e anos de estão na tabela 3.

Tabela 3 - Resultados e conclusões dos artigos sobre o descritor "competências socioemocionais e ensino" com método, autor e ano de cada artigo.

\begin{tabular}{|c|c|c|c|}
\hline AUTORE ANO & TIPODE MĖTODO & RESULTADOS & CONCLUSĀO \\
\hline $\begin{array}{c}\text { (ROCHA ESAMPAIO, } \\
2021 \text { ) }\end{array}$ & $\begin{array}{c}\text { Pesquisa } \\
\text { qualitativa, } \\
\text { desenvolvidas nas } \\
\text { dimensoles } \\
\text { bl bl iograficae } \\
\text { explicativa. }\end{array}$ & 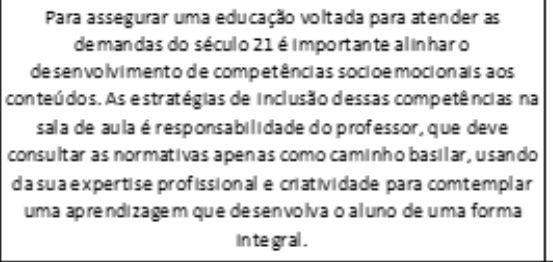 & 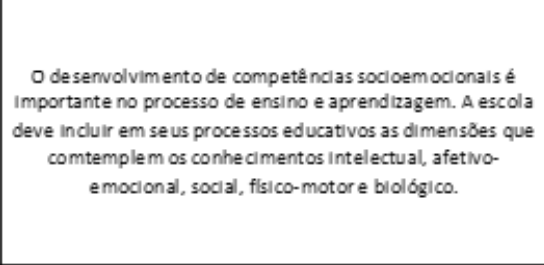 \\
\hline (BARRETO, 2021) & $\begin{array}{c}\text { Pesquisa } \\
\text { bibliográfica e } \\
\text { estudo de caso }\end{array}$ & 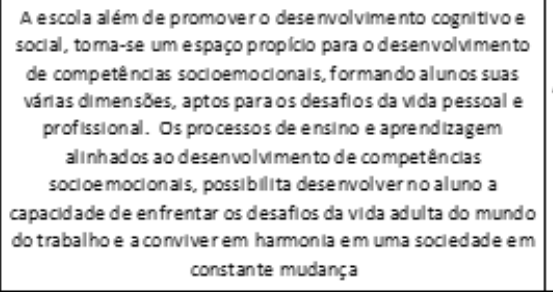 & 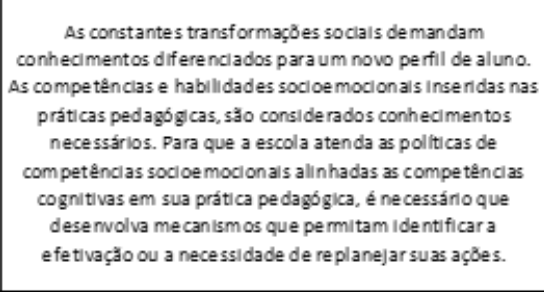 \\
\hline (SANTOS et al., 2018) & $\begin{array}{c}\text { Analise de } 67 \\
\text { resumos de } \\
\text { estud os clentificos }\end{array}$ & 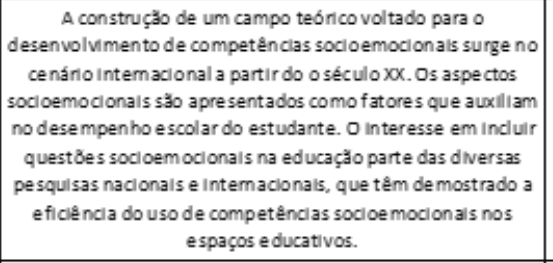 & 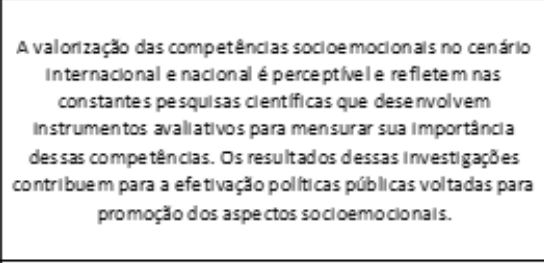 \\
\hline (MARQUESI et al., 2019) & $\begin{array}{c}\text { Revisăo integrativa } \\
\text { da literatura. }\end{array}$ & $\begin{array}{c}\text { Os docentes exercem grande responsabilid ad e nos espaços } \\
\text { escolares, o que de manda de uma ampla carga } \\
\text { socioemocional para trabalhar com os desafios soclals e com a } \\
\text { diversidade emocional dos alunos. O desenvolvimento de } \\
\text { competenclas socioe mocionals para professores toma-se } \\
\text { Importante e contribul para preservar a saúde, e o bem-estar } \\
\text { emocional dos professores, potencializando a qualidade da } \\
\text { atuaçăo prof issional. }\end{array}$ & 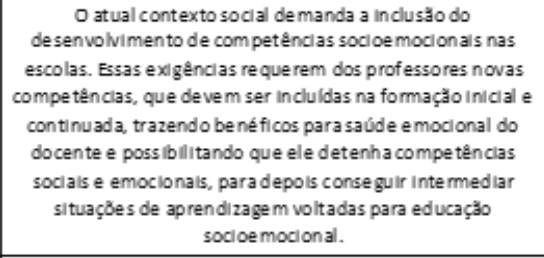 \\
\hline (OLIVEIRA, 2018) & $\begin{array}{l}\text { Conversas } \\
\text { Informals e } \\
\text { observaçăo } \\
\text { participante }\end{array}$ & 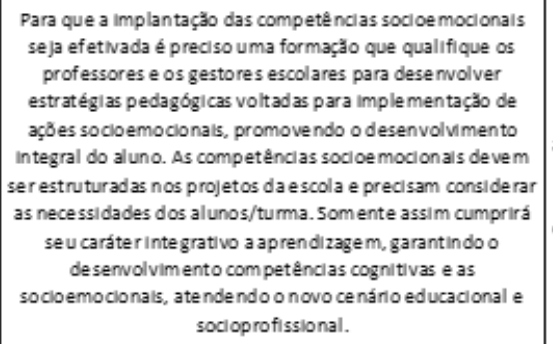 & 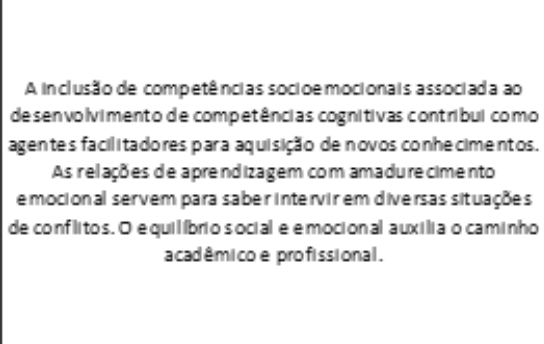 \\
\hline
\end{tabular}

Fontes:(Oliveira, 2018; Santos et al., 2018; Marquesi et al., 2019; Barreto, 2021; Rocha e Sampaio, 2021).

RC: 105205

Disponível em: https://www.nucleodoconhecimento.com.br/educacao/publicacoes-emeducacao 
A tabela 4 mostra os resultados e conclusões dos artigos sobre o descritor "competências socioemocionais e educação profissional" com método, autor e ano de cada artigo

Tabela 4 - Resultados e conclusões dos artigos sobre o descritor "competências socioemocionais e educação profissional" com método, autor e ano de cada artigo.

\begin{tabular}{|c|c|c|c|}
\hline AUTORE ANO & |TPODE MÉTODO & RESULTADOS & CONCLUSĀO \\
\hline (IGNȦCIO et al., 2021) & Pesquisa namrativa & 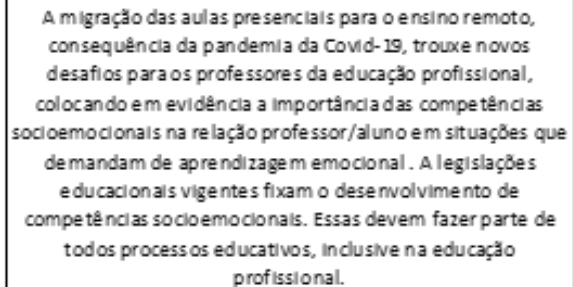 & 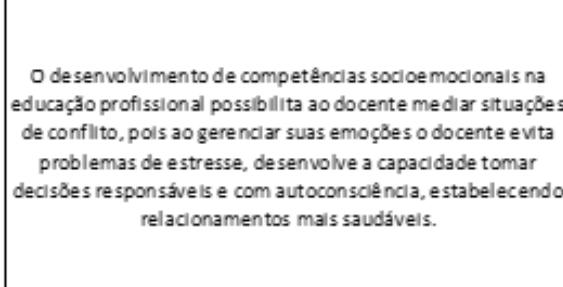 \\
\hline
\end{tabular}

Fonte: (Ignácio et al., 2021)

\section{DISCUSSÃO}

As mudanças no contexto social exigem a formação de um novo perfil de aluno com diversificadas competências para enfrentar as complexas transformações sociais, políticas, econômicas e culturais do século XXI. Essas novas competências devem fazer parte dos itinerários formativos da educação básica, a fim de assegurar um desenvolvimento integral do aluno a partir de competências cognitivas e socioemocionais, seguindo as recomendações da LDB de 1996 e Base Nacional Comum Curricular de 2017 (Pereira e Nascimento, 2021).

A escola é um importante e fundamental espaço para construção de conhecimentos e de desenvolvimento de competências cognitivas e socioemocionais (Santos e Alves, 2020; Chaves e Haiashida, 2021). Essas novas demandas no campo educacional requerem dela o desenvolvimento de competências alinhadas aos conhecimentos cognitivos e emocionais que, somados às práticas educativas, podem contribuir para a formação integral do sujeito (Schorn e Sehn, 2021).

RC: 105205

Disponível em: https://www.nucleodoconhecimento.com.br/educacao/publicacoes-emeducacao 
A instituição educacional não deve se furtar do seu compromisso com o ensino de conteúdo, mas também não pode renegar seu compromisso social, que é contribuir com a melhoria da sociedade e seus sujeitos (Silva e Ferreira, 2020). Ela é importante na incorporação das competências socioemocionais, pois essas possibilitam a formação de sujeitos críticos e éticos, que respeitam as diferenças e desenvolvem também outras características, como autonomia e criatividade (Schorn e Sehn, 2021).

Torna-se então necessária, então, a incorporação das competências socioemocionais nas instituições de ensino, fazendo ajustes nos seus currículos escolares (Santos e Alves, 2020; Silva e Ferreira, 2020; Chaves e Haiashida, 2021; Pereira e Nascimento, 2021; Schorn e Sehn, 2021). O itinerário formativo escolar não deve ter apenas a função de desenvolver aprendizagens baseadas em habilidades cognitivas, mas sim a finalidade de uma educação integral, contemplando em seus currículos o desenvolvimento de competências sociais e emocionais (Ribeiro et al., 2020). Assim há a necessidade de incorporar neles uma educação com práticas pedagógicas e ações que contemplem as dimensões intelectual e socioemocionais, como conhecimentos necessários para formação integral do aluno (Carneiro e Lopes, 2020; Santos e Alves, 2020; Barreto, 2021; Rocha e Sampaio, 2021).

A incorporação das competências socioemocionais é uma demanda decorrente do contexto histórico e social atual (Bissaro e Santos, 2020). Elas deveriam fazer parte dos currículos de toda educação básica, pois são legalmente consideradas como parte integrante dos currículos das escolas brasileiras desde o ano de 2020 (Ribeiro et al., 2020). A escola conseguirá atender as políticas de inclusão de competências quando desenvolver mecanismos que permitam identificar sua efetivação, priorizando seus objetivos e alinhando suas ações para desenvolvimento das competências cognitivas e socioemocionais (Barreto, 2021).

A política de inclusão de competências nas escolas aponta para a necessidade da formação continuada dos professores. A partir da apropriação desse conhecimento é que eles entenderão a importância das competências socioemocionais e seus

RC: 105205

Disponível em: https://www.nucleodoconhecimento.com.br/educacao/publicacoes-emeducacao 
benefícios. Estes ultrapassam os limites das escolas, contribuindo para vida pessoal e profissional do aluno (Lucena et al., 2021). A falta de conhecimento docente tornase um desafio na tentativa de desenvolver as competências socioemocionais em seus alunos (Chaves e Haiashida, 2021). Antes de desenvolvê-las nos alunos, é preciso munir o professor de competências e estratégias que permitam não apenas implementar as competências socioemocionais, mas que esse seja um trabalho coerente com os objetivos e dotado de intencionalidade (Resende, 2020).

Com a implementação da BNCC em 2017 ficou visível o interesse dos professores por conhecimentos voltados para temática (Carneiro e Lopes, 2020), mesmo diante da escassez de estudos que que relacionam competências socioemocionais à docência, é crescente o interesse pela temática voltada para atender às novas exigências da sociedade contemporânea (Lisboa e Rocha, 2021). Essas novas exigências requerem dos professores novas competências, que devem ser incluídas na formação inicial e continuada, trazendo benefícios para saúde emocional do docente. Isso possibilita que ele detenha competências sociais e emocionais, para depois conseguir intermediar situações de aprendizagem voltadas para educação socioemocional perante seus alunos (Marquesi et al., 2019).

A Resolução CNE/CP 02/2019 para a formação inicial de professores da Educação Básica e Base Nacional Comum e para a Formação Inicial de Professores da Educação Básica (BNC-Formação), descreve que o

"[...] conhecimento pedagógico sobre a relação entre docente e alunos e o processo de ensino e aprendizagem, que, colocados em prática, favorecem o desenvolvimento integrado de competências cognitivas e socioemocionais (Brasil, 2019a)".

Isso significa que os professores devem ser capazes de conhecer amplamente as competências socioemocionais para ser capaz de utilizá-las, juntos com os conhecimentos formais, em sala de aula (Brasil, 2019a).

RC: 105205

Disponível em: https://www.nucleodoconhecimento.com.br/educacao/publicacoes-emeducacao 
Uma pesquisa sobre a importância do desenvolvimento das competências socioemocionais em sala de aula, realizada com 12 docentes da educação básica, mostrou que as dimensões socioemocionais dos alunos influenciam de forma positiva ou negativa em seu processo de aprendizagem. Isso alerta para a importância de desenvolver o aluno em seus aspectos tanto cognitivo quanto emocional (Carneiro e Lopes, 2020).

As relações de aprendizagem com amadurecimento emocional servem para saber intervir em diversas situações de conflitos. $O$ equilíbrio social e emocional auxilia o caminho acadêmico e profissional (Oliveira, 2018). As competências socioemocionais são conhecimentos indispensáveis para o sucesso do sujeito e sua relevância é também reconhecida nas diferentes áreas do conhecimento (Silva et al., 2020).

Um aluno que tem suas competências socioemocionais desenvolvidas apresenta maior facilidade em aprender os conteúdos formais escolares (Oliveira, 2019). Geralmente é capaz de desenvolver relacionamentos saudáveis na escola e em outros contextos sociais, evitando comportamentos agressivos e conflituosos (Silva e Ferreira, 2020). O desenvolvimento socioemocional na escola, integrado aos conhecimentos de conteúdo, possibilita uma formação integral, influenciando positivamente nas relações atuais e futuras do aluno (Carneiro e Lopes, 2020).

A discussão acerca da implementação das competências socioemocionais na educação para formação integral do sujeito, encontra-se nos documentos base da educação, evidenciando que além do desenvolvimento pleno da pessoa e deve assegurar uma educação para o exercício da cidadania e da qualificação para o trabalho (Brasil, 1996; 2019).

Na Educação Profissional e Tecnológica (EPT) alguns projetos políticos pedagógicos (PPPs) incluem a resolução de problemas, tanto para docentes como para discentes. Os docentes devem levar em conta, no planejamento e execução de práticas pedagógicas, a resolução de problemas (Alves e Kaiser, 2020).

RC: 105205

Disponível em: https://www.nucleodoconhecimento.com.br/educacao/publicacoes-emeducacao 
O docente EPT tem formações distintas e, muitas vezes, diversas da área da licenciatura. Transitando no mundo não acadêmico eles muitas vezes trazem em si a prática de resolução de problemas e tem maior interação social. Aliado a este fato, o treinamento stricto sensu, constante na carreira EPT, possibilita o uso dos conhecimentos gerados em pesquisa para incrementar a solução de problemas (Neto, 2020).

É esperado que, assim, os discentes ensinados por eles apliquem os conhecimentos formais, tomem decisões responsáveis e resolvam problemas do dia a dia (Alves e Kaiser, 2020). Diferentes metodologias empregadas promovem a aprendizagem e fazem o aluno EPT pensar de forma comunitária e autônoma, o que facilita o enfrentamento de problemas reais (Seibel, 2020).

Um projeto desenvolvido em uma instituição de ensino EPT, na área de educação física, contribuiu para o desenvolvimento das competências socioemocionais em discentes do ensino médio técnico. Os alunos relataram, ao final da experiência, que, apesar da competição existente, a cooperação entre equipes predominou. 0 autocontrole, autonomia, autoestima e independência foram as metas alcançadas neste projeto. As instituições de ensino EPT parecem ser um lugar propício para desenvolvimento destas competências (Viana et al., 2020).

A formação integral e omnilateral que norteia os institutos federais de educação profissional e tecnológica, permite que os discentes tenham uma experiência em estágios muito superior aos discentes de mesmo nível no ensino regular. Essa experiência de trabalhar em empresas aumenta o repertório socioemocional do aluno. O estágio apresenta a ele não só o conceito de trabalho, como a convivência social e educativa, e problemas que devem ser solucionados (Costa, 2020).

RC: 105205

Disponível em: https://www.nucleodoconhecimento.com.br/educacao/publicacoes-emeducacao 


\section{CONCLUSÕES}

As teorias sobre implantação de competências socioemocionais na educação parecem indicar objetivos, mas nota-se uma ausência de propostas concretas que possam ser executadas ou gradualmente implantadas. É preciso identificar quais competências são necessárias e quais podem ser desenvolvidas no ambiente escolar. Isso permitiria quantificar e qualificar sua contribuição para o desenvolvimento social e emocional de professores e alunos.

Apesar das legislações educacionais apresentarem a necessidade de inclusão das competências socioemocionais, elas não apresentam uma base fundamentada e nem como essas devem ser organizadas. As políticas educacionais parecem exigir a inclusão de competências socioemocionais nos currículos da educação básica, porém ocorre a falta de capacitação dos professores. São eles os principais agentes na formação direta dos discentes em sala de aula.

A reestruturação dos currículos deveria também abranger situações diárias de ensino que fossem possíveis de serem realizadas, a partir da reorganização dos espaços pedagógicos, alinhado às estratégias de ensino fundamentadas nas competências.

A modernização dos currículos com a inclusão de competências socioemocionais proporciona aos alunos uma formação integral (omnilateral). Essa formação contribui com o aprendizado formal em sala de aula e, indo além, é capaz de influenciar positivamente a sua atuação profissional, quando adulto.

$\mathrm{Na}$ Educação profissional e Tecnológica (EPT) o saber técnico-profissional deve ser para além de uma formação de conteúdo, preparando os discentes para enfrentarem situações reais da futura profissão e para superarem desafios e problemas. Isso demanda uma formação que contemple as dimensões sociais e emocionais (competências socioemocionais).

RC: 105205

Disponível em: https://www.nucleodoconhecimento.com.br/educacao/publicacoes-em$\underline{\text { educacao }}$ 
A condução de mais pesquisas a respeito da inclusão de competências socioemocionais em ambientes de ensino é importante. As ações educativas costumam partir de fora deste ambiente. A vida adulta, e a vida no trabalho, exige comportamentos e conhecimentos que o aluno utilizará em sua prática social e profissional, fora do ambiente escolar. E que o docente utilizará para conduzir seus discentes em um aprendizado integral.

\section{REFERÊNCIAS}

ALVES, L. A.; KAISER, J. P. S. Letramento científico na EPT: o que nos diz o projeto pol'ítico pedagógico do IFRN. Labor, v. 1, n. 24, p. 11-23, 2020.

\section{AZEVEDO, V. C. F. D. Competências Socioemocionais De Gestores De Escolas} Públicas. 2019. 34p. (Graduação). Universidade Federal da Paraíba, João Pessoa PB.

BARRETO, D. D. M. Desenvolvimento de competências socioemocionais: desafios em uma escola técnica. ECCOM, v. 12, n. 23, p. 263-272, 2021. Disponível em: < http://publicacoes.unifatea.edu.br/index.php/ECCOM/article/view/1284/1173 >.

BISSARO, D. Z.; SANTOS, D. Z. Educação do campo: um estudo em defesa de um currículo voltado para as competências socioemocionais. Kiri-kerê: Pesquisa em Ensino, v. 2, n. 4, p. 101-119, 2020.

BRASIL. LEI № 9.394, DE 20 DE DEZEMBRO DE 1996 - Estabelece as diretrizes e bases da educação nacional. Brasilia DF: Casa_Civil 1996.

. Base Nacional Comum Curricular (BNCC). Brasilia DF: MEC 2017.

. Constituição da República Federativa do Brasil. Brasilia DF: STF: 577 p. 2019.

RC: 105205

Disponível em: https://www.nucleodoconhecimento.com.br/educacao/publicacoes-emeducacao 
. Diretrizes Curriculares Nacionais para a Formação Inicial de Professores para a Educação Básica e BaseNacional Comum para a Formação Inicial de Professores da Educação Básica (BNC-Formação). Brasilia DF, 2019a. Disponível em: < http://portal.mec.gov.br/index.php?option=com_docman\&view=download\&alias=1330 91-pcp022-19-3\&category_slug=dezembro-2019-pdf\&ltemid=30192 >. Acesso em: 30 nov 2021.

. Resolução no 1 de 05 de janeiro de 2021. Diretrizes Curriculares Nacionais Gerais para a Educação Profissional e Tecnológica. Brasilia DF: CNE 2021.

CAPES. Treinamento no uso do Portal de Periódicos. Brasilia DF, 2012. Disponível em: < https://www.fca.unesp.br/Home/Biblioteca/portal-capes.pdf >. Acesso em: 06 set 2021.

CARNEIRO, M. D. L.; LOPES, C. A. N. Desenvolvimento das Competências Socioemocionais em Sala de Aula. Revista multidisciplinar e de psicologia, v. 154, n. 53, p. 1-14, 2020.

CARVALHO, A. M. A. O que é "social" para a psicologia? Temas em Psicologia, n. 3, p. 1-17, 1994.

CARVALHO, R. S.; SILVA, R. R. D. Currículos socioemocionais, habilidades do século XXI e o investimento econômico na educação: As novas políticas curriculares em exame. Educar em Revista, n. 63, p. 173-190, 2017.

CERICATO, I. L.; CERICATO, L. Competências Socioemocionais de Bolso: formando alunos e professores para os desafios do séc. XXI. 1. São Paulo SP: Editora do Brasil, 2019. 66p.

CHAVES, C. M.; HAIASHIDA, K. A. Abordagem das competências socioemocionais no ensino remoto. Ensino em Perspectivas, v. 2, n. 3, p. 1-10, 2021.

RC: 105205

Disponível em: https://www.nucleodoconhecimento.com.br/educacao/publicacoes-emeducacao 
COSTA, R. A. P. Estágio na educação profissional técnica de nível médio: A formação no mundo do trabalho 2020. 180p. (Mestrado). Universidade Federal da Bahia, Salvador BA.

GONÇALVES, G. P. Implementação da política de desenvolvimento das competências socioemocionais: Um estudo de caso na EEFM João Mattos. 2019. 107 (Mestrado Profissional ). Universidade Estadual Do Ceará, Fortaleza CE.

IGNÁCIO, F.; RAMIREZ, R. A.; BERGAMO, R. O. C. Competências socioemocionais e educação profissional: práticas docentes em ensino remoto. Revista Interdisciplinar em Educação e Territorialidade - RIET, v. 2, n. 2, p. 246 263, 2021.

LISBOA, A. C.; ROCHA, P. A. M. Competências socioemocionais e docência: a BNCC e as novas exigências na formação de professores. In: CASTRO, P. A. D. (Ed.). Educação como (re)Existência: mudanças, conscientização e conhecimento. Campina grande: Ralize Editora, v.1, 2021. p.1-26.

LUCENA, V.; OLIVEIRA, S.; MANFRÉ, A. H. As competências socioemocionais e o processo de ensino e de aprendizagem escolar. ENEPE. Presidente Prudente SP: $2339-2353$ p. 2021.

MARIN, A. H. et al. Competência socioemocional: conceitos e instrumentos associados. Revista Brasileira de Terapias Cognitivas, v. 13, n. 2, p. 92-103, 2017.

MARINHO-ARAUJO, C. M.; RABELO, M. L. Avaliação educacional: a abordagem por competências. Avaliação: Revista da Avaliação da Educação Superior, v. 20, n. 2, p. 443-466, 2015.

MARQUESI, A. M.; HIROMI, T. L.; FÓZ, A. Q. B. Avaliação de programas de intervenção para a aprendizagem socioemocional do professor: Uma revisão integrativa. Revista Portuguesa de Educação, v. 32, n. 1, p. 35-51, 2019.

RC: 105205

Disponível em: https://www.nucleodoconhecimento.com.br/educacao/publicacoes-emeducacao 
MORAES, P. E. H. Currículo formal e informal e situações interpessoais como condições que afetam a autoavaliação sobre habilidades sociais e competência social de estudantes de Psicologia. 2020. (Mestrado). Universidade Federal de São Carlos, São Carlos SP.

MORAIS, F. A. D. Emoções no Contexto da Educação Profissional e Tecnológica: contribuições para a compreensão do trabalho emocional docente. 2019. 66p. (Doutorado). Universidade Federal da Bahia, Salvador BA.

NETO, A. F. D. S. A Formação Continuada De Professores Da Educação Profissional E Tecnológica (EPT) Brasileira. 2020. 91p. (Mestrado). UNIJUí, ljuí RS.

OLIVEIRA, M. E. As Competências Socioemocionais, Formação Cidadã e Projeto de Vida: um diálogo possível no chão da escola. Campina Grande PB, 2018. Disponível em: < https://editorarealize.com.br/artigo/visualizar/46422 >. Acesso em: 02 dez 2021.

OLIVEIRA, M. E. Os desafios da implementação das Competências Socioemocionais na sala de aula. VI CONEDU. Fortaleza CE: 1-12 p. 2019.

PEREIRA, W. C.; NASCIMENTO, F. D. C. B. Nível das competências socioemocionais de alunos do ensino médio no contexto da pandemia de covid 19. Revista Docentes, v. 6, n. 15, p. 11-19, 2021.

PERRENOUD, P. 10 novas competências para ensinar : convite à viagem Porto Alegre RS: Artmed, 2014. 192p.

RESENDE, D. M. P. O papel das competências socioemocionais: visão multidisciplinar de agentes educativos. 2020. 42p. (Mestrado). Universidade Católica Portuguesa, Porto PT. 
RIBEIRO, C. F. et al. Inteligências e Competências Socioemocionais: o papel das ETECs no desenvolvimento de Soft Skills. XV Simpósio Dos Programas De Mestrado Profissional Unidade De Pós-Graduação, Extensão E Pesquisa. São Paulo SP: Centro Estadual de Educação Tecnológica Paula Souza: 313-322 p. 2020.

ROCHA, M. D. M.; SAMPAIO, M. A. P. A importância do desenvolvimento das competências socioemocionais para a aprendizagem: Uma revisão de literatura. In: GONÇALVES, M. C. D. S. e JESUS, B. G. D. (Ed.). Educação Contemporânea. Belo Horizonte MG: Poisson, v.17, 2021. p.49-58.

SANTOS, G. M. D.; ALVES, J. F. D. S. Competências socioemocionais na escola: tão imprescindíveis quanto os conteúdos e as práticas educativas, um requisito para a formação integral do estudante. In: ANDRADE, D. F. (Ed.). Série Educar - Reflexões. Belo Horizonte MG: Poisson, 2020. cap. 08, p.57 - 63.

SANTOS, M. V. D. et al. Competências Socioemocionais: Análise da Produção Científica Nacional e Internacional. Gerais: Revista Interinstitucional de Psicologia, v. 11, n. 1, p. 04-10, 2018.

SCHORN, S. C.; SEHN, A. S. Competências socioemocionais: Reflexões sobre a educação escolar no contexto da pandemia. Rio Grande do Sul: UNIJUI: 1-16 p. 2021.

SEIBEL, M. K. Ensino Híbrido Na Educação Profissional E Tecnológica Como Possibilidade Didática Na Formação Crítica Do Aluno. 2020. 155p. (Mestrado). Instituto Federal Do Espírito Santo, Vitória ES.

SILVA, A. D. Análise de Competências Socioemocionais de Gestores Escolares na Cidade de Santa Rita - PB. 2019. 37p. (Graduação). Universidade Federal da Paraíba, João Pessoa PB. 
SILVA, B. B. D. C.; FERREIRA, M. C. P. L. Educação socioemocional e suas repercussões no contexto escolar. 2020. Disponível em: < http://repositorio.aee.edu.br/jspui/bitstream/aee/17050/1/EDUCA\%c3\%87\%c3\%830 \%20SOCIOEMOCIONAL\%20E\%20SUAS\%20REPERCUSS\%c3\%95ES\%20NO\%20 CONTEXTO\%20ESCOLAR.pdf >. Acesso em: 05 dez 2021.

SILVA, J. S. D.; SANTOS, I. R. D.; SAMPAIO, M. A. P. Competências socioemocionais: Um mapeamento sistemático de literatura no Estado do Tocantins. Anais VII CONEDU. Maceio AL: Realize Editora 2020.

SILVA, M. M. C. O desenvolvimento de componentes socioemocionais como forma de prevenção ao bullying na escola: uma análise das competências gerais da BNCC. 2020. Universidade Estadual do Rio Grande do Sul, Cruz Alta RS.

VIANA, V. N.; OLIVEIRA, E. D.; DIAS, C. A. G. M. O Papel Da Educação Física Na Ept - De Nilo Peçanha ao Instituto Federal. In: VIANA, V. N. e DIAS, C. A. G. M. (Ed.). Educação física e EPT. São Paulo: Centro de Pesquisa, v.1, 2020. cap. 1, p.07-14.

Enviado: Janeiro, 2022.

Aprovado: Janeiro, 2022.

RC: 105205

Disponível em: https://www.nucleodoconhecimento.com.br/educacao/publicacoes-emeducacao 